\title{
The Relationship Between Eyebrow Elevation and Height of the Palpebral Fissure: Should Postoperative Brow Descent be Taken into Consideration When
} Determining the Amount of Blepharoptosis Correction?

Edward Ilho Lee ${ }^{1}$, Nam Ho Kim², Ro Hyuk Park ${ }^{2}$, Jong Beum Park ${ }^{2}$, Tae Joo $\mathrm{Ahn}^{2}$

\section{${ }^{1}$ Division of Plastic Surgery, Baylor College of Medicine, Houston, TX, USA; ${ }^{2}$ Gyalumhan Plastic Surgery, Seoul, Korea}

This article was presented at the 71th Congress of the Korean Society of Plastic and Reconstructive Surgeons (1st Asian blepharoplasty forum) on November 1-3, 2013 in Seoul, Korea.

No potential conflict of interest relevant to this article was reported.
Background Combining blepharoptosis correction with double eyelid blepharoplasty is common in East Asian countries where larger eyes are viewed as attractive. This trend has made understanding the relationship between brow position and height of the palpebral fissure all the more important in understanding post-operative results. In this study, authors attempt to quantify this relationship in order to assess whether the expected postoperative brow descent should be taken into consideration when determining the amount of ptosis to correct.

Methods Photographs of ten healthy female study participants were taken with brow at rest, with light elevation and with forceful elevation. These photographs were then viewed at $2 \times$ magnification on a computer monitor and caliper was used to measure the amount of pull on the eyebrow in relation to the actual increase in vertical fissure of the eye.

Results There was a positive, linear correlation between amount of eyebrow elevation and height of the palpebral fissure, which was statistically significant. Brow elevation increased vertical fissure, and thereby aperture of the eye, by $18 \%$.

Conclusions Although the eye-opening strength as well as height of the palpebral fissure is improved with ptosis repair, the true effectiveness of ptosis surgery is diminished by the associated descent of the brow from relief of the involuntary frontalis muscle action and this should be taken into account prior to surgical intervention. Regardless, the combination of frontalis muscle relaxation and the increased eyeopening strength from ptosis repair gives the eye and the periorbital region a more natural look.

Keywords Blepharoptosis, Muscles, Face
Received: Jan 14, 2014 Revised: Feb 15, 2014 Accepted: Feb 17, 2014 Correspondence: Tae Joo Ahn Gyalumhan Plastic Surgery, 21st Mijinplaza, 390 Gangnam-daero, Gangnam-gu, Seoul 135-934, Korea.

E-mail: cmcanti@hanmail.net

Copyright @ 2014 The Korean Society for Aesthetic Plastic Surgery.

This is an Open Access article distributed under the terms of the Creative Commons Attribution Non-Commercial License (http://creativecommons.org/licenses/by-nc/3.0/) which permits unrestricted non-commercial use, distribution, and reproduction in any medium, provided the original work is properly cited. $\quad w w w . e-a a p s . o r g$

\section{INTRODUCTION}

The importance of the eye in defining a person's impression is well known. In East Asian countries, the desire to look westernized brought the advent of double eyelid surgery around turn of the 19th century, with Mikamo publishing the first report of doubleeyelid surgery in Japan [1]. As a specific form of blepharoplasty, the double-eyelid surgery has evolved over time to adapt to innovations in technique as well as changing cultural and social preferences. Moreover, it has become increasingly common in East Asian 

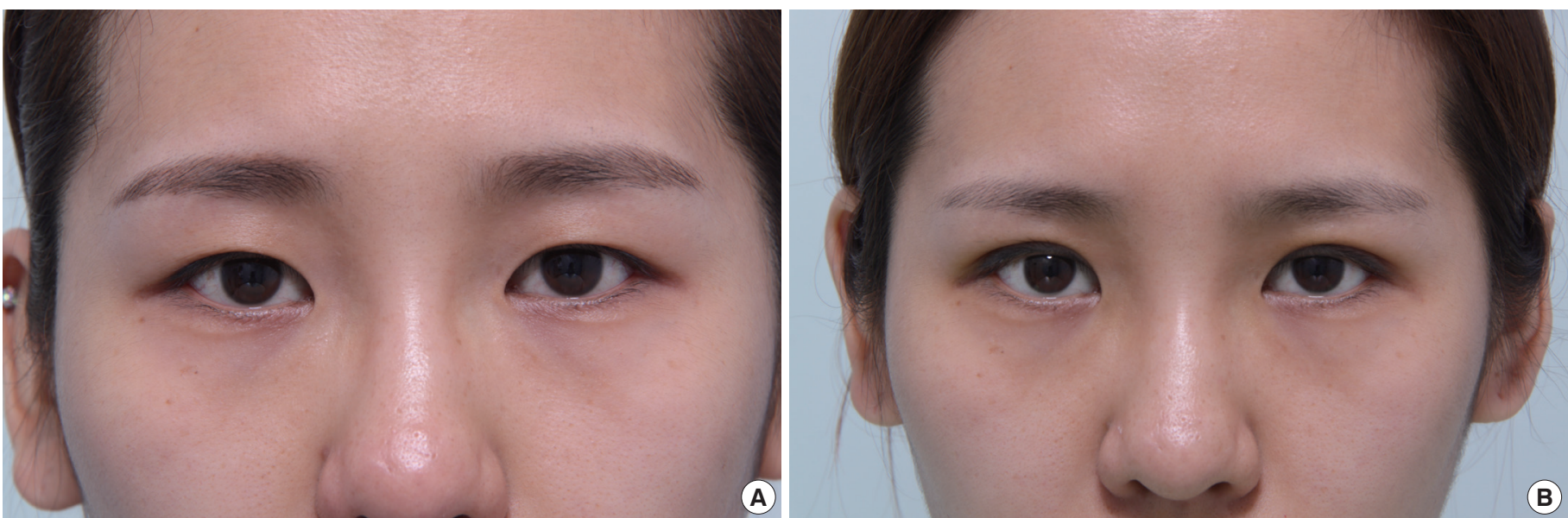

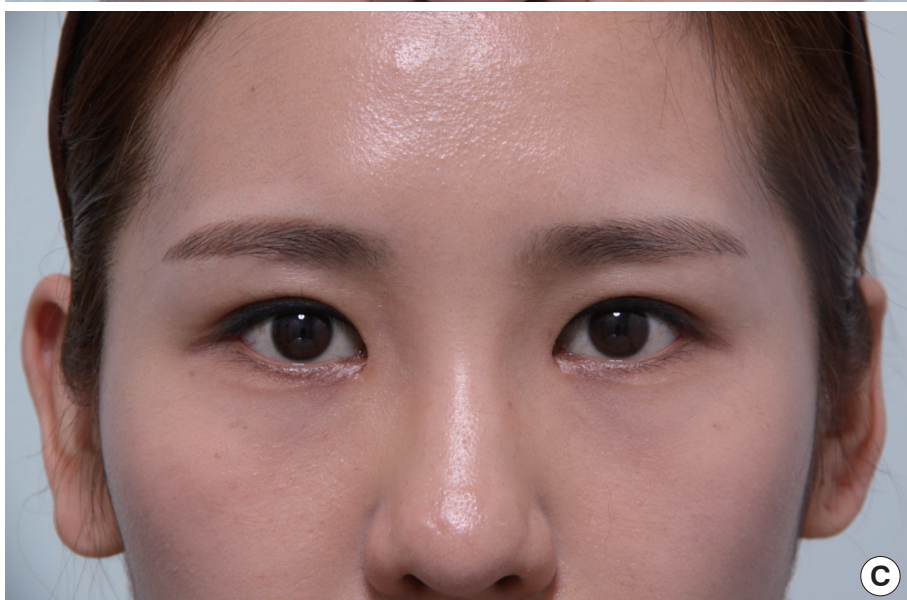

countries to utilize blepharoptosis repair techniques in conjunction with double eyelid blepharoplasty for the aesthetic purpose of increasing the aperture of the eye, which is viewed as more attractive in this patient population [2-4]. However, the concept of combining these techniques is not new and is used around the world [5-7].

One important outcome of such combination of procedures is the evidence for the intimate relationship and interplay between adjacent perioccular muscles. In cases of weak eyelid elevation, frontalis muscle is utilized to augment the poorly functioning levator palpebrae [8]. The frontalis muscle not only reduces the strain on the upper eyelid to compensate for the ptosis, but also assists in opening of the eye. As such, patients with blepharoptosis commonly have elevated eyebrows and, in these patients, there is gradual resolution of this involuntary brow elevation upon ptosis correction. Because of such phenomenon, it is often difficult to assess the true benefit gained from combination of double eyelid blepharoplasty and blepharoptosis repair as it relates to the increase in height of the palpebral fissure (Fig. 1).

In this study, the interaction between these various perioccular muscles is analyzed to assess whether a relationship exists between eyebrow elevation and change in vertical fissure of the eye. In ad-
Fig. 1. 30 year old female. (A) pre-operative image shows involuntary elevation of eyebrows at rest; (B) 1 week post-operative image after simultaneous blepharoptosis correction and double eyelid blepharoplasty with Muller's muscle tucking through triangular stitch method (2). One can already see the natural descent of eyebrows at rest; (C) 42-day post-operative image shows more rested and natural appearance around the periorbital region.

dition, the extent of this relationship is quantified to assess whether the expected postoperative brow descent should be taken into account when determining the amount of blepharoptosis to correct.

\section{METHODS}

Ten healthy female study participants were enrolled after obtaining written consent. All study participants presented to senior author of this paper for evaluation for double eyelid surgery.

First, patient was asked to keep her eyes open and to maintain this opening at rest (Fig. 2). Next, a medical assistant was asked to elevate patient's eyelid by applying manual pressure on junction of the eyebrow and forehead at mid-pupillary line with her thumb, first with light force, followed by maximum force. Photographs were taken at these three points - at rest, with light elevation, and with forceful elevation - with a ruler placed in line with medial canthus at the medial upper eyelid/eyebrow junction. This was repeated twice for each patient for total of 3 cycles per patient ( 9 photographs). The same assistant was used for all patients.

Photographs were then viewed at $2 \times$ magnification on a computer monitor and caliper was used to measure the amount of pull 

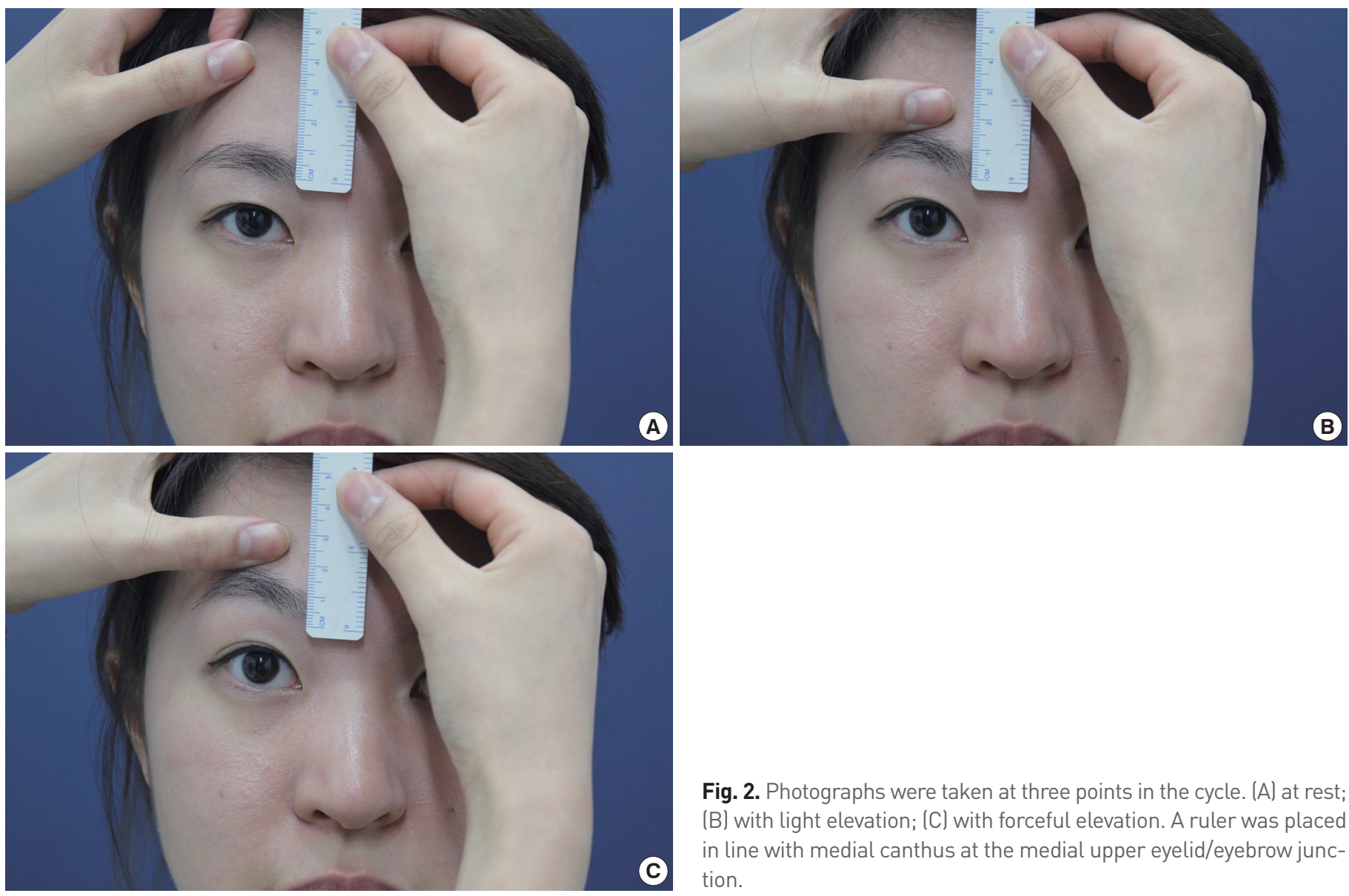

Fig. 2. Photographs were taken at three points in the cycle. (A) at rest; (B) with light elevation; (C) with forceful elevation. A ruler was placed in line with medial canthus at the medial upper eyelid/eyebrow junction.
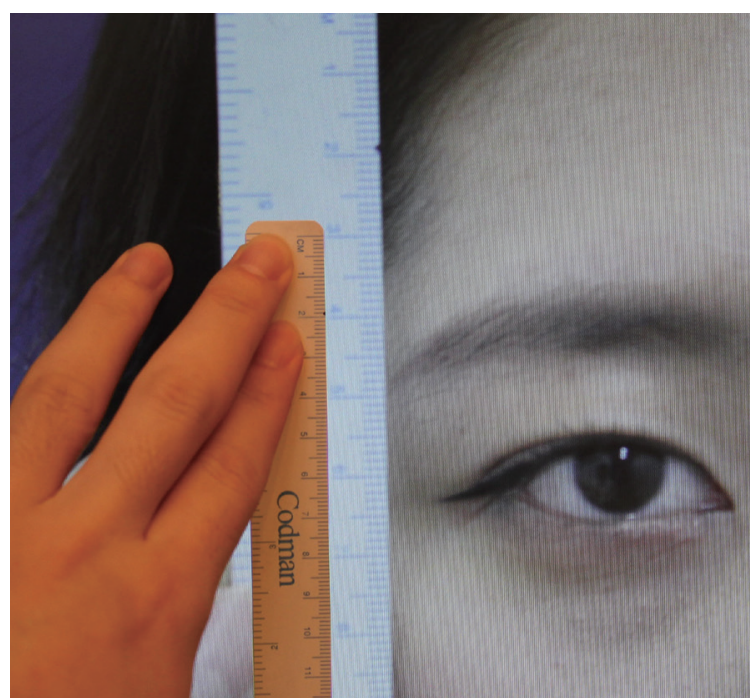

(A)
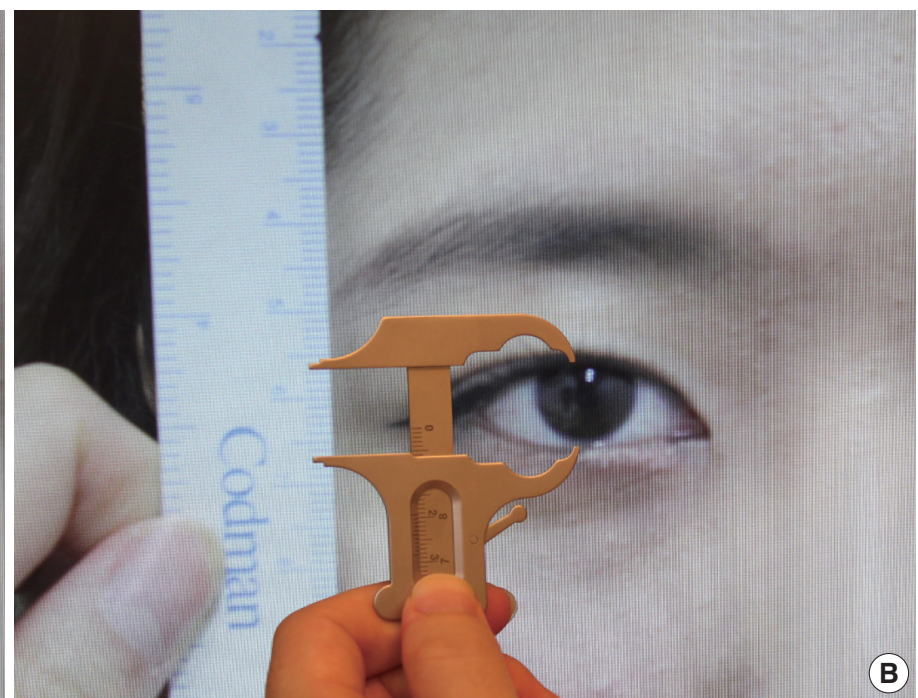

Fig. 3. (A) Photographs were viewed at $2 \times$ magnification on a computer monitor such that the increment in the photograph was twice that of the increment on the ruler placed on top of the monitor; (B) Caliper was then used to measure the amount of pull on the eyebrow in relation to the actual increase in vertical fissure of the eye.

on the eyebrow in relation to the actual increase in vertical fissure of the eye (Fig. 3). The degree of magnification was such that the ruler increment in the photograph was twice that of the ruler placed on top of the monitor. This magnification allowed for more accurate measurement with the caliper.

Data points were tabulated measuring the change in brow and 
Table 1. Data points were tabulated measuring the change in brow and eyelid height with each cycle and with each incremental force on the brow (at rest, light force, maximum force). Cycle \#1 for Patient \#8 was excluded from analysis because the images were out of focus and not amenable to accurate measurement

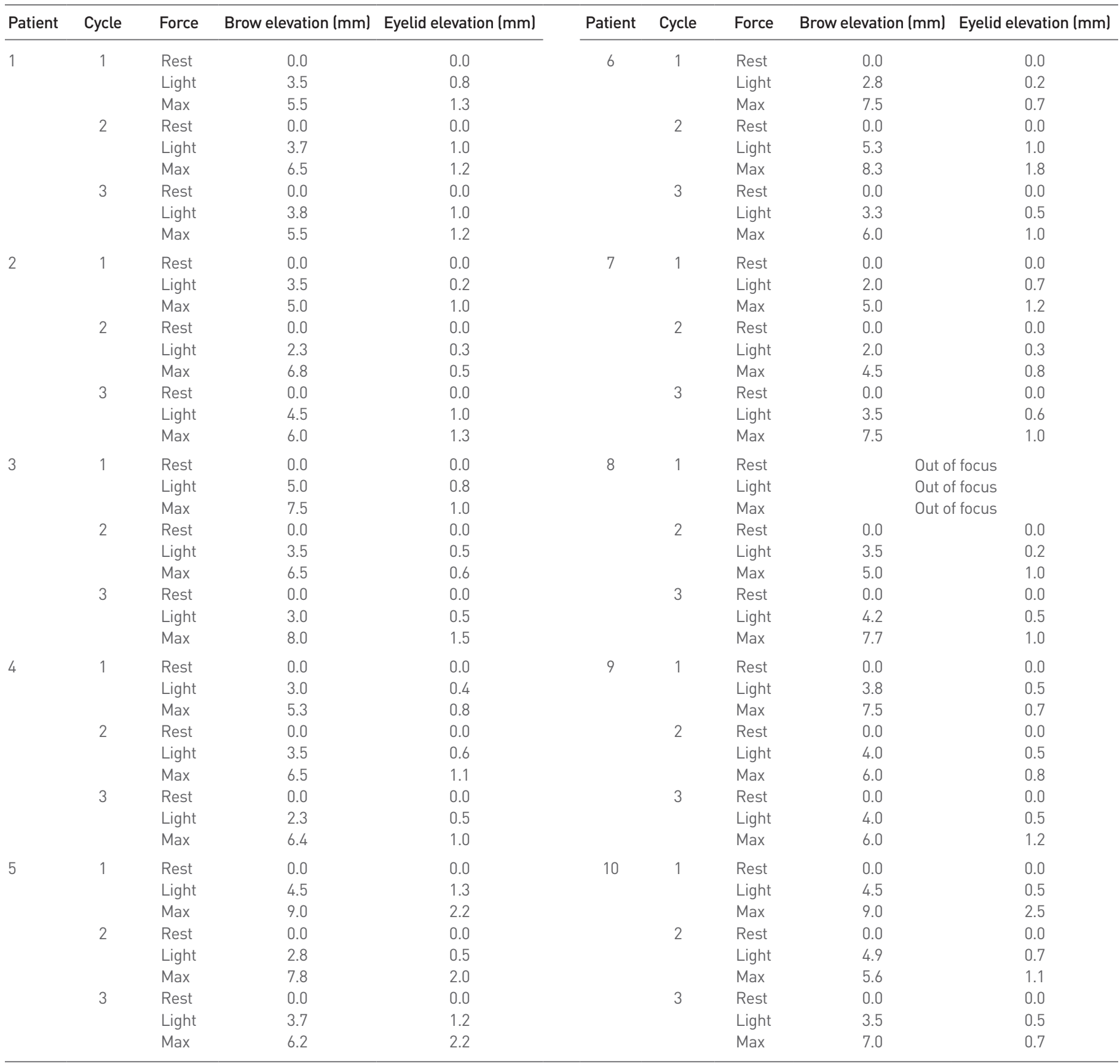

eyelid height with each cycle (Table 1). The eyebrow and eyelid height at rest was set at zero and the incremental change in their respective height, first with light elevation followed by forceful elevation, was measured (in millimeters). One of the cycles for one of the patients (Patient \#8) was excluded from analysis because the images were out of focus and not amenable to accurate measurement. Given the hypothesis that there is a relationship between eyebrow elevation (independent variable) and height of the vertical fissure (dependent variable), a linear regression model was used for statistical analysis. Data points were plotted and a trend line was calculated through linear regression model using InStat ${ }^{\circledR}$ Version 3.1a statistical software (GraphPad, Inc., La Jolla, California). Values of $\mathrm{P}<0.05$ were considered statistically significant. 


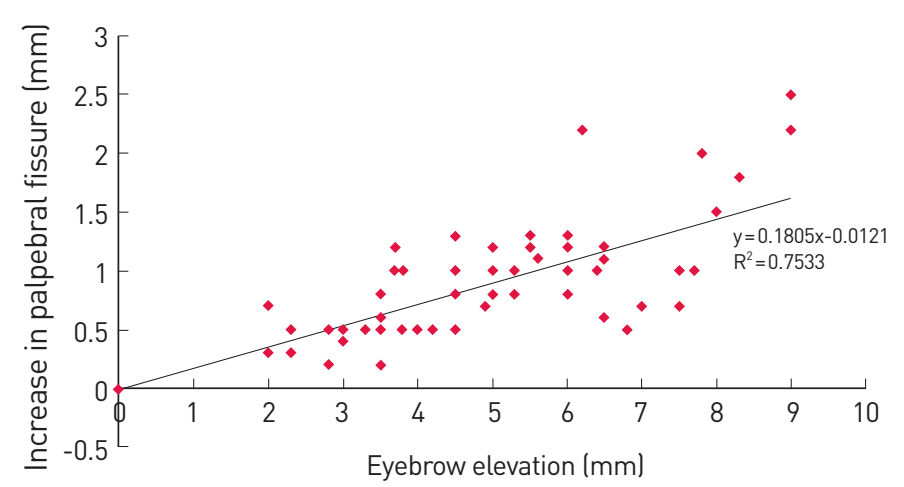

Fig. 4. There was a positive, linear correlation between amount of eyebrow elevation and height of the palpebral fissure. The change in vertical height of the palpebral fissure can be predicted with eyebrow elevation by the following formula: $y=0.1805 x-0.0121, R^{2}$ (coefficient of determination) $=0.753$. This correlation was statistically significant $(P<0.0001)$.

\section{RESULTS}

There was a positive, linear correlation between amount of eyebrow elevation and height of the palpebral fissure (Fig. 4). The change in vertical height of the palpebral fissure can be predicted with eyebrow elevation by the following formula: $y=0.1805 x-$ $0.0121, \mathrm{R}^{2}$ (coefficient of determination) $=0.753$. This correlation was statistically significant $(\mathrm{P}<0.0001)$.

In another words, brow elevation will increase vertical fissure, and thereby increase aperture of the eye, by approximately $18 \%$. If one were to elevate the eyebrow by $10 \mathrm{~mm}$, this will increase size of the eye by $1.8 \mathrm{~mm}$. That is to say, if ptosis correction is able to reduce involuntary eyebrow elevation by $10 \mathrm{~mm}$, this can be seen as increasing vertical fissure and, therefore, eye opening by $1.8 \mathrm{~mm}$.

\section{DISCUSSION}

The strong interplay between forehead, eyebrow and eyelid in periorbital aesthetics is well known [8]. Moreover, the astute surgeon understands the importance of careful preoperative assessment of these three structures in order to obtain optimal surgical results. The degree of pre-operative ptosis, the position and shape of each structure, as well as any underlying asymmetry should be accounted for before undertaking any surgical intervention.

There are some controversies, however, regarding brow position after upper eyelid procedures such as blepharoplasty or ptosis correction. Some studies suggest that the brow position remains unchanged after blepharoplasty $[9,10]$ whereas others report that there is change in brow position whether or not this change is clinically significant [11-14].

Fagien reported his analysis of eyebrow position in 15 patients with measurable eyebrow ptosis who underwent upper eyelid blep- haroplasty without concomitant browpexy [11]. Eleven patients showed an insignificant change in their eyebrow position, whereas 2 patients had mild to moderate brow descent and 2 patients had what was felt to be significant worsening of the ptosis. However, all patients were pleased with their results. Trolius, on the other hand, demonstrated in 10 patients that upper blepharoplasty decreased brow height on average of $3.3 \mathrm{~mm}, 3.6 \mathrm{~mm}$, and $3.3 \mathrm{~mm}$ at the medial canthus, pupil and lateral canthus, respectively [12].

Prado et al. [13] evaluated 45 patients without preoperative ptosis or previous brow surgeries who underwent upper eyelid blepharoplasty and concluded that the removal of redundancy of eyelid tissue accentuated the tendency of brow to move down.

Lastly, Lee et al. [14] evaluated brow position after upper blepharoplasty or levator advancement and concluded that both procedures shortened the distance between eyelid margin and the brow. The change in brow height was greater in the levator advancement group but the postoperative brow height in the levator advancement group was still higher.

Our study was designed to determine whether the height of the palpebral fissure changes with varying degree of eyebrow elevation. To best of our knowledge, no other studies have attempted to quantify this relationship.

Through our analysis, we were able to find statistically significant correlation between these two factors. Each incremental increase in eyebrow elevation will increase height of the palpebral fissure, as measured from mid-pupillary line, by $18 \%$. Clinically, we can then predict that although the eye-opening strength as well as height of the palpebral fissure is improved with ptosis surgery, the true effectiveness of ptosis surgery is diminished by the associated descent of the brow from relief of the involuntary frontalis muscle action.

Indeed, our clinical experience supports our finding that although the actual gain in height of the palpebral fissure may not be apparent when viewing the eye by itself, the combination of frontalis muscle relaxation and the increased eye-opening strength from ptosis repair give the eye and the periorbital region a more natural appearance (Fig. 1).

In addition, by having the ability to quantify the association between brow elevation and height of the palpebral fissure, one can predict that the degree of ptosis correction is effectively reduced by the resulting brow descent. Therefore, ptosis should be overcorrected by $18 \%$ in order to obtain the desired increase in the postoperative height of the palpebral fissure (ie., correction obtained $=$ calculated ptosis correction needed $+18 \%$ of measured height of preoperative eyebrow elevation).

One potential limitation of this study is the small sample size. However, data was collected to arrive at a linear regression model and although $\mathrm{R}^{2}$ did not reach 1 , there was a strong correlation with $\mathrm{R}^{2}=0.753$. In addition, the slope of the regression line was statistically significant $(\mathrm{P}<0.0001)$. 
Another potential limitation is the inclusion of only young, Korean female participants. Other studies have shown that there are age, gender and ethnic differences in brow and eyelid topography [15-18]. Further study incorporating these factors may be useful.

It is hoped that our data will improve on the accuracy of predicting the change in both brow position and height of the palpebral fissure after blepharoplasty and/or ptosis correction. Post-operative brow descent should be taken into consideration when determining the amount of blepharoptosis correction and this potential change should be explained to the patients.

\section{REFERENCES}

1. Shirakabe Y, Kinugasa T, Kawata M, et al. The double-eyelid operation in Japan: its evolution as related to cultural changes. Ann Plast Surg 1985;15:224-41.

2. Ahn TJ. Blepharoptosis correction with stitch method. J Korean Soc Aesthetic Plast Surg 2010;16:140-3.

3. Kim JH, Lee IJ, Park MC, et al. Aesthetic blepharoptosis correction with release of fibrous web bands between the levator aponeurosis and orbital fat. J Craniofac Surg 2012;23:e52-5.

4. Li J, Lin M, Zhou H, et al. Double-eyelid blepharoplasty incorporating blepharoptosis surgery for 'latent' aponeurotic ptosis. J Plast Reconstr Aesthet Surg 2011;64:993-9.

5. Martin JJ Jr. Ptosis repair in aesthetic blepharoplasty. Clin Plast Surg 2013;40:201-12.

6. Massry GG. Ptosis repair for the cosmetic surgeon. Facial Plast Surg Clin North Am 2005;13:533-9.

7. Older JJ. Ptosis repair and blepharoplasty in the adult. Ophthalmic Surg
1995;26:304-8.

8. Flowers RS, Caputy GG, Flowers SS. The biomechanics of brow and frontalis function and its effect on blepharoplasty. Clin Plast Surg 1993; 20:255-68.

9. Starck WJ, Griffin JE Jr, Epker BN. Objective evaluation of the eyelids and eyebrows after blepharoplasty. J Oral Maxillofac Surg 1996;54:297302.

10. Frankel AS, Kamer FM. The effect of blepharoplasty on eyebrow position. Arch Otolaryngol Head Neck Surg 1997;123:393-6.

11. Fagien S. Eyebrow analysis after blepharoplasty in patients with brow ptosis. Ophthal Plast Reconstr Surg 1992;8:210-4.

12. Troilius C. Subperiosteal brow lifts without fixation. Plast Reconstr Surg 2004;114:1595-603.

13. Prado RB, Silva-Junior DE, Padovani CR, et al. Assessment of eyebrow position before and after upper eyelid blepharoplasty. Orbit 2012;31: 222-6.

14. Lee JM, Lee TE, Lee $H$, et al. Change in brow position after upper blepharoplasty or levator advancement. J Craniofac Surg 2012;23:434-6.

15. van den Bosch WA, Leenders I, Mulder P. Topographic anatomy of the eyelids, and the effects of sex and age. Br J Ophthalmol 1999;83: 347-52.

16. Matros E, Garcia JA, Yaremchuk MJ. Changes in eyebrow position and shape with aging. Plast Reconstr Surg 2009;124:1296-301.

17. Rhee SC, Woo KS, Kwon B. Biometric study of eyelid shape and dimensions of different races with references to beauty. Aesthetic Plast Surg 2012;36:1236-45.

18. Price KM, Gupta PK, Woodward JA, et al. Eyebrow and eyelid dimensions: an anthropometric analysis of African Americans and Caucasians. Plast Reconstr Surg 2009;124:615-23. 